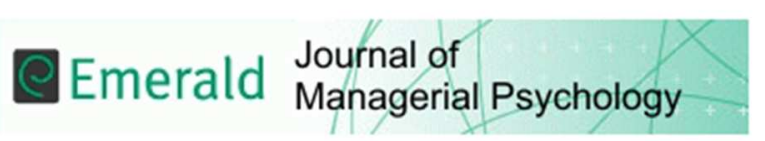

\title{
Job enlargement, job crafting and the moderating role of self-competence
}

\begin{tabular}{|r|l|}
\hline Journal: & Journal of Managerial Psychology \\
\hline Manuscript ID: & JMP-01-2014-0019.R3 \\
\hline Manuscript Type: & Research Paper \\
\hline Keywords: & $\begin{array}{l}\text { Organizational behavior, Employee behaviour, Human resource } \\
\text { management }\end{array}$ \\
\hline \multicolumn{2}{|l}{} \\
\hline
\end{tabular}

SCHOLARONE

Manuscripts 


\section{Introduction}

After a fundamental contribution by Wrzesniewski and Dutton (2001) was published, job crafting received increasing attention within the literature on proactivity. Job crafting has been described as "an exciting area of research" (Oldham and Hackman, 2010, p. 470) because of its relevance in terms of rethinking the role of workers in areas such as job design (Oldham and Hackman, 2010), work satisfaction and well-being (Tims et al., 2013a), work engagement and performance (Bakker et al., 2012), quality of work (Leana et al., 2009), proactive adaptations (Berg et al., 2010b), learning (Kira et al., 2010) and change (Petrou et al., 2012).

Although several research results are already available, the role of organizational context and individual differences in facilitating or inhibiting job crafting is still relatively unexplored (Berg et al., 2013, Grant and Ashford, 2008). This paper's contribution to such research is twofold. In the job crafting model created by Tims and Bakker, which is based on the Job Demands - Resources (JD-R) approach, job crafting is described as an individual initiative aimed at modifying the level of available demands and resources to improve the person - job fit (Tims and Bakker, 2010). In this paper, we build upon such a model to clarify whether a relevant job contextual characteristic, such as job enlargement, may facilitate employees' job crafting initiatives aimed at changing their structural and social resources.

Second, we analyze the role of self-competence as a moderator between job enlargement and job crafting behaviors. Several authors argue that personal resources (e.g., self-competence) play a significant role in influencing proactive behaviors (for a review see Tornau and Frese (2013) and, specifically on job crafting, see Tims and Bakker (2010)). Thus, in this paper we ask whether perceived self-competence moderates the relation between job enlargement and job crafting. We specifically focus on job crafting behaviors aimed at increasing structural and social resources. We do not consider other job crafting behaviors, such as increasing 
challenging demands and decreasing hindering demands, because job crafting is a general, composite construct, comprising a variety of different behaviors. According to Wrzesniewski and Dutton (2001), job crafters do not necessarily craft their jobs in all possible ways, so it seems reasonable to consider different types of job crafting behaviors in relation to different research questions. In our study, we considered job crafting behaviors that seem to be directly related to antecedents such as job enlargement and self-competence.

\section{Job crafting}

The literature on job crafting began with a fundamental contribution by Wrzesniewski and Dutton (2001). The authors define job crafting as "the physical and cognitive changes individuals make in the task or relational boundaries of their work" (Wrzesniewski and Dutton, 2001, p. 179). They identify three different types of job crafting behaviors: i) changing task boundaries; ii) changing relational boundaries; iii) changing cognitive task boundaries. According to this model, the motivation for job crafting arises from three basic individual needs (need for control, need for a positive self-image and the need for human connections). Job crafting may be facilitated or inhibited by job characteristics (i.e., autonomy, interdependence), general motivational orientations (i.e., intrinsic versus extrinsic motivations), or work orientation (i.e., seeing work as a job, a career, or a calling). It generates consequences in terms of work design, social environment at work, meaning of work and work identity. Thus, job crafting is a proactive and adaptive process (Berg et al. 2010b) through which employees craft their job by adding tasks, emphasizing tasks or redesigning tasks to respond to unanswered occupational callings, achieve a greater level of task variety and identity (Berg et al., 2010a) and enrich the meaning of their work (Wrzesniewski et al., 2003). Research shows that both personal characteristics, such as selfimage, perceived control, readiness to change (Lyons, 2008), and interpersonal dynamics 
(Leana et al., 2009) may have a significant role in shaping job crafting. Additionally, it is shown that job crafting may lead to improved individual performance (Bakker et al., 2012) or group performance (Tims et al., 2013b) through higher work engagement. A recent study by Tims et al. (2013a) illustrates a positive relation between job crafting, job satisfaction, burnout reduction and workers' well-being. These authors adopt the Job Demands Resources (JD-R) job crafting model (Tims and Bakker, 2010), which, in turn, is based on the more general JD-R work model (Demerouti et al., 2001). Tims and Bakker (2010) propose that employees craft their jobs by taking initiatives aimed at changing their job demands and job resources. Job demands refer to the physical, social or organizational job characteristics that require sustained physical and/or psychological effort. Job resources refer to the physical, psychological, social or organizational elements of the job that allow workers to achieve goals and facilitate their personal development (Demerouti et al., 2001). Examples of job demands are workload, time pressure and role conflicts. Examples of job resources are job security, team climate, opportunity for skill utilization, skill variety and autonomy (for a review see Bakker and Demerouti (2007)). Tims et al. (2012) propose a key distinction between social resources and structural resources. Structural resources refer to elements such as autonomy, responsibility, capabilities and knowledge of the job, whereas social resources refer to elements such as support from colleagues, feedback and supervisory coaching. This distinction is particularly important. First, it allows for focus on significantly different job crafting behaviors. Second, it helps to understand how workers proactively relate to different aspects of their working life, such as work and task structure on the one hand, and social structure on the other. According to the JD-R job crafting model (Tims and Bakker, 2010, Tims et al. 2012), workers may attempt to increase their job resources (both structural and social) to obtain valuable individual outcomes (e.g., work engagement and job satisfaction). Additionally, they may try to increase their challenging job demands to achieve mastery 
experiences, which, in turn, may lead to increased satisfaction and engagement. Finally, they may try to decrease hindering job demands as exposure to such demands may lead to negative consequences, such as burnout and reduced work engagement. Overall, workers craft their jobs to achieve a better balance between demands and resources (Tims et al., 2012).

\section{Research hypothesis}

\section{The relationship between job enlargement and increasing structural and social resources}

Few studies have explored empirically the relationship between work organization and job crafting. Available research shows that task complexity and task discretion predict relational crafting (Ghitulescu, 2006). Similarly, a combination of high day-level work pressure and high day-level autonomy (active jobs) may increase the number of initiatives aimed at seeking resources (Petrou et al., 2012), even though the influence of discretion on job crafting is quite articulated given that it may vary at different ranks (Berg et al., 2010b). Additionally, job control may facilitate job crafting (Lyons, 2008). Overall, these studies indicate that different work features may have a significant effect on job crafting. On the one hand, job stressors may trigger proactivity when individuals perceive a gap between their current work situation and a desired one as they try to fill that gap through job crafting initiatives (Tims and Bakker, 2010). On the other hand, job characteristics such as job autonomy, control, skill variety, task identity and task significance may stimulate initiatives (Bindl and Parker, 2010; Grant and Ashford, 2008) and proactive behaviors (Ohly and Fritz, 2009) by increasing motivation (Demerouti et al., 2001), work engagement (Bakker et al., 2012), satisfaction and well-being (Tims et al., 2013a). Such characteristics also decrease exhaustion and cynicism (Bakker et al., 2004) and, overall, encourage behaviors aimed at preserving and accumulating job resources (Hakanen et al., 2008). This process is known as "gain spiral", which is described 
by Conservation of Resources (COR) theory (Hobfoll, 1989). According to COR theory, individuals are constantly engaged in retaining and building resources to protect themselves from stress and burnout as well as to increase well-being. Llorens et al. (2007) illustrate such a process empirically by showing that "efficacy beliefs play a mediating role between task resources and engagement, and engagement increases efficacy beliefs, which, in turn, increase task resources over time" (Llorens et al., 2007, p. 825). Similarly, Hakanen et al. (2008) observed a cyclical relationship between job resources, work engagement, personal initiative and work-unit innovativeness.

Job enlargement is a well-established job design approach through which the variety of tasks and required skills defining a certain job are increased. Parker (1998, p. 837) showed that job enlargement, by providing "regular and ongoing opportunities for enactive mastery", increases self-efficacy, which is a relevant antecedent for proactivity (Parker et al., 2006). At the same time, skill variety may improve the meaningfulness of work and promote a flexible role orientation (Parker et al., 1997), again an antecedent for proactive behavior (Parker et al., 2006). Other researchers focused on how task variety increases personal initiatives through increased feelings of vigor and dedication (Salanova and Schaufeli, 2008). Thus, although the available literature suggests that job enlargement positively affects antecedents of proactivity, we still have no evidence about its direct effect on job crafting. We try to help in filling such gap by hypothesizing a positive relationship between job enlargement and two specific forms of job crafting, "increasing (or seeking) structural resources" and "increasing (or seeking) social resources", as defined by Tims and Bakker (2010) and Tims et al. (2012). In the job crafting literature, "increasing" and "seeking" resources are used synonymously as they both refer to workers' behaviors aimed at accumulating resources (Tims and Bakker., 2010) The combination of two theoretical arguments justifies these hypotheses. In general, because the available evidence shows that job enlargement positively affects relevant antecedents of 
proactivity, it seems reasonable to assume that it will also positively affect a specific type of proactivity, such as job crafting. More specifically, the "gain spiral" effect, proposed by COR theory, suggests that such a positive effect of job enlargement on job crafting may be particularly relevant for specific behaviors aimed at accumulating resources. Thus, we hypothesize the following:

H1 There is a positive relationship between job enlargement and increasing structural resources.

H2 There is a positive relationship between job enlargement and increasing social resources.

\section{The moderating role of self-competence}

Self-competence concerns the assessment by an individual of his/her own skills and abilities in relation to a certain activity or domain (Ford, 1985). Tafarodi and Swann (2001, p. 654) defined self-competence as "the valuative experience of oneself as a causal agent, an intentional being that can bring about desired outcomes through exercising its will". Thus, when individuals perceive themselves to be competent in a certain domain, they expect to be able to achieve a high level of performance. Several studies show that self-competence is positively related to organizational commitment (Mathieu and Zajac, 1990) and work satisfaction (Bhagat and Allie, 1989). Additionally, self-competence helps individuals sustain performance in the face of obstacles (Freedman and Phillips, 1985) by increasing effort and persistence in pursuing goals, and reducing depersonalization and emotional exhaustion in stressful situations (Bhagat and Allie, 1989).

As a significant personal resource, we argue that self-competence may play a significant role in motivating job crafters. Indeed, Tims and Bakker (2010) claim that individual differences may act as moderating variables within the JDR job crafting model. More specifically, we 
hypothesize that self-competence positively moderates the relation between job enlargement and increasing structural resources. The rationale is that highly self-competent workers may have stronger beliefs about their own ability to assess the value of job resources in relation to their work tasks and challenges. Additionally, they may have stronger beliefs about their ability to increase their structural resources either by re-combining existing ones or by identifying completely new resources altogether. Thus, when job enlargement increases, workers with a higher level of self-competence will be more confident about their ability to cope with the new challenges (brought by the enlarged job) through the acquisition of new resources. On the contrary, workers with a lower level of self-competence facing an enlarged job will be less confident about their ability to acquire the necessary resources, so they may be less inclined to take initiatives to increase them. We can summarize our argument in the following hypothesis:

H3 Self-competence moderates the positive relationship between job enlargement and increasing structural job resources. This relationship is stronger for individuals with a higher level of self-competence.

We also hypothesize that self-competence negatively moderates the relation between job enlargement and increasing social resources. In other words, as job enlargement increases, individuals with higher self-competence will seek social resources comparatively less than individuals with lower self-competence.

To explain our rationale, we need to consider two different aspects about behaviors aimed at increasing social support. On the one hand, the literature shows that such behaviors imply a perceived social cost. When individuals seek support from others, they are showing implicitly that they lack an adequate level of knowledge and/or ability to do their job. For this reason, 
“individuals do not seek help, even when help is needed and available, because help seeking implies incompetence and dependence" Lee (1997, p. 336). On the other hand, the literature also emphasizes an instrumental motive for seeking social support. The evidence shows that the need to master new problems and activities increases feedback-seeking behaviors (Miller and Jablin, 1991). Thus, when individuals perceive that they lack the ability or the competence needed for the task, they rely on their social environment by seeking feedback (Ashford and Black, 1996).

Overall, the literature shows two opposite phenomena: the perceived social cost should keep individuals from seeking social support, whereas the instrumental motive should motivate people to seek social support. We propose that our hypothesis about the negative moderating role of self-competence should be understood in the context of these two opposing phenomena.

When job enlargement is low (low task and skill variety), most individuals will perceive a significant level of social cost in seeking social support. They will feel likely to be negatively judged by others (colleagues, bosses, etc.) for not being self-sufficient in a relatively "simple" work context, where task variety and required skill variety are low.

However, when job enlargement increases, the perceived social cost will increase comparatively more for highly self-competent people, whereas the instrumental motive will increase comparatively more for low self-competent people. On the one hand, individuals with a low level of self-competence will feel more socially legitimized to ask for help because of the higher task and skill variety implied by the enlarged job. Individuals with a high level of self-competence will instead be less inclined to seek help from others because they will feel that their competence will be under the scrutiny of others specifically in relation to more challenging, enlarged work situations. Thus, the social cost argument seems to suggest that 
self-competence negatively moderates the relation between job enlargement and the search for social support.

Additionally, when job enlargement increases, the perceived instrumental value of social support increases significantly for workers with low self-competence because, given the higher challenge that an enlarged job provides, they will feel that such support is absolutely necessary to successfully accomplish their tasks. Moreover, the instrumental value of social support will increase comparatively less for workers with high self-competence because they will feel a lower need of external support to perform their job successfully. Thus, the instrumental motive also suggests, just like the social cost argument, that self-competence has a negative moderating effect on the relation between job enlargement and seeking social resources.

Both arguments (social cost and instrumental motive) contribute to a rationale for our hypothesis. As job enlargement increases, individuals with high self-competence should be relatively less inclined to seek social resources. For them, social costs should increase comparatively more, whereas the instrumental motive should increase comparatively less. The opposite should hold true for individuals with lower self-competence. We can summarize our arguments in the following hypothesis:

H4 Self-competence negatively moderates the positive relationship between job enlargement and increasing social resources, so that such a relationship is weaker for individuals with a higher level of self-competence

\section{Methods}

Participants and procedures 
We gathered our data within a major retail company. Participation in the research, which involved store-level workers, was voluntary. Although these workers operate in different store aisles and departments, their tasks are identical, e.g., merchandising, re-stocking and customer assistance. Indeed, the company considers their formal organizational position as being the same. Additionally, they receive the same training and have the same work contracts.

We distributed 200 questionnaires together with a cover letter explaining the research goals. Each participant was reassured about the anonymity of the survey. To ensure anonymity even further, respondents were asked to put the survey inside a security box, which was opened a month after the distribution of the questionnaires. We obtained 158 correctly filled questionnaires, yielding an overall response rate of approximately $80 \% ; 51 \%$ of overall respondents were female; the average age was 40 years old, with a minimum of 19 and a maximum of 69 ; the average company tenure was 12.5 years.

\section{Measures}

As respondents' native language was Italian, each measuring scale was translated by a professional translator. To validate the translation, we utilized the back translation method (Brislin et al., 1973).

We measured Job Enlargement through three items developed by Parker (1998) that emphasize the way a certain job gives the opportunity to perform a range of different tasks, use a variety of skills and make full use of possessed skills. A typical item used is: "To what extent does your job allow you to make full use of your skills?” The response scale goes from 1 (not at all) to 5 (a great deal).

We measured Increasing Structural Resources and Increasing Social Resources through two sub-dimensions of the job crafting scale developed by Tims et al. (2012). Each scale included 
five items. For example, an item for Increasing Structural Resources was "I try to develop my capabilities", whereas an item for Increasing Social Resources was "I ask colleagues for advice". The respondents were asked to indicate how often they engage in each behavior from 1 (never) to 5 (very often).

We measured Self Competence through a self-competence sub-scale of the Self-Liking/ SelfCompetence revisited scale developed by Tafarodi and Swann (2001). This sub-scale includes eight items. A typical item is "I am highly effective at the things I do". At the beginning of each item, we added "At work". Items were scored on a scale ranging from 1 (strongly disagree) to 5 (strongly agree).

Control variables. We controlled for tenure because previous research shows that it may influence job crafting behaviors (Berg et al., 2010b). The nature of such influence is not clear. On the one hand, short tenured employees may be more inclined to proactively shape their jobs, whereas long tenured employees may become more habituated to the job and treat it as a fixed entity. On the contrary, it is also possible that longer-tenured members enjoy more control in changing their jobs and/or have a better understanding of available opportunities for job crafting thanks to a deeper knowledge of the organizational context.

We also controlled for gender. Research findings suggest a mixed picture about the influence of gender on proactive behaviors. Men were found to be more proactive then women both in terms of proactive job search, networking behaviors and voicing concerns about issues in the workplace. However, these results are not solid as there are methodological issues suggesting that further research is needed to clarify the relevance of gender (Bindl and Parker, 2010).

\section{Results}

Table 1 shows the descriptive statistics and correlations among variables, and provides preliminary support to research hypotheses $\mathrm{H} 1$ and H2, i.e., Job Enlargement is positively 
correlated to both Increasing Structural Resources $(\mathrm{r}=0.34, \mathrm{p}<0.01)$ and Increasing Social Resources $(\mathrm{r}=0.23, \mathrm{p}<0.01)$. Moreover, the common tests presented in Table 1 confirm reliability of the scales.

\section{[TABLE 1 ABOUT HERE]}

We studied the structural validity of the scales used in the analysis by performing a confirmatory factor analysis in AMOS. We compared the four-factor model with both a threefactor model in which all 10 items related to Job Crafting (five for Increasing Structural Resources and five for Increasing Social Resources) loaded on a single latent variable, and with a single-factor model where we constrained all observed items to load on a single latent variable. In all instances, we allowed the latent variables to correlate with each other. The four-factor model exhibits an acceptable fit $\left[\chi^{2}=369.5 \quad(\mathrm{df}=183), \mathrm{CFI}=0.90, \mathrm{IFI}=0.90\right.$, TLI $=0.88$, RMSEA $=0.06]$, whereas both the three-factor model $\left[\chi^{2}=540.6 \quad(\mathrm{df}=186)\right.$, $\mathrm{CFI}=0.71, \quad \mathrm{IFI}=0.72, \mathrm{TLI}=0.67, \mathrm{RMSEA}=0.10]$ and the single-factor model $\left[\chi^{2}=812.9\right.$ $(\mathrm{df}=189), \mathrm{CFI}=0.439, \mathrm{IFI}=0.45, \mathrm{TLI}=0.36, \mathrm{RMSEA}=0.148]$ show a poorer fit of the data. Moreover, a chi-squared difference test supports the superiority of the four-factor model with respect to both the three-factor $\left[\Delta \chi^{2}=171.1(\mathrm{df}=3), \mathrm{p}<0.01\right]$ and the single-factor model $\left[\Delta \chi^{2}=443.4(\mathrm{df}=6), \mathrm{p}<0.01\right]$. Finally, following Aiken and West (1991), we mean-centered all variables and we noted that the mean variance inflation factor (VIF) is always below the threshold level of 5 (Studenmund, 2009), suggesting that multicollinearity is not an issue in our analysis.

Table 2 below shows regression results conducted to test our initial set of hypotheses. In the first step, gender and tenure were entered as control variables (Model 1). 


\section{[TABLE 2 ABOUT HERE]}

Tenure was the only variable found to be significantly associated to both Increasing Structural Resources and Increasing Social Resources, whereas gender showed a statistically significant coefficient for only Increasing Social Resources. In the second step, we added the independent and moderating variables (Model 2). According to both $\mathrm{H} 1$ and $\mathrm{H} 2$, the association between Job Enlargement and Increasing Structural Resources (H1) and Increasing Social Resources (H2) is positive and statistically significant (with coefficients, respectively, of $\beta=0.20, \mathrm{p}<0.01$ and $\beta=0.29, \mathrm{p}<0.01$ ). Moreover, Self-Competence is significantly related to both Increasing Structural Resources $(\beta=0.25, \mathrm{p}<0.01)$ and Increasing Social Resources $(\beta=-0.28, \mathrm{p}<0.01)$. Finally, in the last step of the regression we added the interaction terms (Model 3).

Contrary to H3, Self-Competence did not moderate the relation between Job Enlargement and Increasing Structural Resources $(\beta=-0.05, p=0.5)$. However, consistent with H4, SelfCompetence did moderate the relation between Job Enlargement and Increasing Social Resources $(\beta=-0.33, \mathrm{p}<0.05)$. As shown in Figure 1 , the relation was weaker for individuals who were higher in Self-Competence.

[FIGURE 1 ABOUT HERE]

\section{Discussion}

As we expected, we found that job enlargement is positively associated with both job crafting behaviors that we considered in our study. This is consistent with previous literature arguing that a more resourceful job may incentivize proactivity (Grant and Ashford, 2008). It is also consistent with COR theory and its "gain spiral" argument (Hobfoll, 1989). Thus, a job design practice, such as job enlargement, may have a trigger effect on resource seeking 
efforts. Contrary to our expectations, we did not find that self-competence moderates the relationship between job enlargement and increasing structural resources. A possible explanation may be found on how the need for competence varies at different levels of selfcompetence. Wrzesniewski and Dutton (2001, p. 183) argued that "motivation to craft a job most often will result from situations in which employees feel that their needs are not being met in their job as it is currently designed". Notably, Sheldon and Gunz (2009) found empirical support for the needs-as-motives hypothesis, specifically in relation to the need for competence. According to their study, a perceived need for competence will increase motivation to fulfill such a need (Sheldon and Gunz, 2009). Thus, it is possible that workers with low self-competence will perceive a comparatively stronger need for competence and, consequently, a stronger motivation to fulfill their need by seeking structural resources. This effect might counter-balance the positive moderating effect that we hypothesized.

Finally, we found that self-competence negatively moderates the relationship between job enlargement and increasing social resources, as expected. In situations where jobs are more enlarged, individuals with higher self-competence are comparatively less prone to craft their jobs by seeking support from others because the perceived social cost associated with such behavior increases more, whereas their perceived instrumental value increases less (in relation to individuals with lower self-competence).

\section{Managerial implications}

Our research supports the idea that both the contextual and psychological aspects significantly influence the way individuals craft their jobs by proactively developing their job resources. We found a positive relationship between job enlargement and job crafting behaviors aimed at developing resources. In this perspective, job crafting can be seen as a "costless form of informal on-the-job training" (Petrou et al., 2012, p. 1137). Thus, our results suggest that 
organizations interested in supporting self-regulated forms of personnel development may benefit from implementing job design practices, such as job enlargement, that create organizational conditions favorable to job crafting.

Our results also suggest that highly self-competent individuals may be reluctant to seek social resources, especially within work environments characterized by enlarged jobs, because of the higher social costs and the lower instrumental value that they associate with seeking such resources. This may be particularly problematic in knowledge-based organizations, where overall performance depends heavily on effective information sharing. In this respect, managerial interventions aimed at changing the organizational culture may be useful to lower perceived social costs and increase the perceived instrumental value of social exchanges. For example, Lee (1997) showed the relevance of organizational norms of individualism and collectivism in orienting members' behavior towards either independence or interdependence in relation to their social context. In the first case, individuals are more inclined to focus on their own resources and efforts. In the second case, they are more inclined to collaborate and cooperate. When the latter type of organizational norm is prevalent, perceived social costs to seeking social resources may decrease. Thus, by decreasing individualism (through communication, training etc.), managers might be able to encourage highly self-competent people to be less reluctant in seeking out social resources, thereby increasing information and knowledge sharing.

\section{Limits and further research paths}

The most significant limitation of our study is its cross-sectional, single source design. This did not allow us to establish the causal relationship between variables. We hypothesized that enlarged jobs may lead to increased job crafting initiatives (aimed at increasing structural and 
social resources). However, a reciprocal relationship might also exist. Future research may establish whether our results hold true in longitudinal, multiple source studies.

Another limitation concerns the nature of self-reported measures. However, we believe that our methodology, which ensured complete protection of respondents' identity, reduced the evaluation apprehension and the common method variance (Podsakoff et al., 2003). Additionally, a specific analysis utilizing Harman's single-factor test confirmed that the variables in our study did not load onto a single factor.

Finally, we focused exclusively on some work characteristics (those defining an enlarged job). Other work contextual elements (task significance, amount of feedback, etc.) may also be relevant, as suggested by Petrou et al. (2012). Further research on the relationship between job characteristics and job crafting is certainly needed.

\section{References}

Aiken, L.S. and West, S.G. (1991), Multiple Regression Testing and Interpreting Interactions, Sage, Newbury Park, CA.

Ashford, S.J. and Black, J.S. (1996), “Proactivity during organizational entry: Antecedents, tactics, and outcomes”, Journal of Applied Psychology, Vol. 81 No. 2, pp. 199-214.

Ashford, S.J., Blatt, R. and VandeWalle, D. (2003), "Reflections on the Looking Glass: A Review of Research on Feedback-Seeking Behavior in Organizations”, Journal of Management, Vol. 29 No. 6, pp. 773-799.

Ashford, S.J. and Cummings, L.L. (1983), "Feedback as an individual resource: Personal strategies of creating information", Organizational Behavior and Human Performance, Vol. 32 No. 3, pp. 370-398. 
Ashford, S.J. and Cummings, L.L. (1985), “Proactive feedback seeking: The instrumental use of the information environment", Journal of Occupational Psychology, Vol. 58 No. 1, pp. $67-79$.

Bakker, A.B. and Demerouti, E. (2007), "The Job Demands-Resources model: state of the art”, Journal of Managerial Psychology, Vol. 22 No. 3, pp. 309-328.

Bakker, A.B., Demerouti, E. and Verbeke, W. (2004), "Using The Job Demands-Resources Model To Predict Burnout And Performance”, Human Resource Management, Vol. 43 No. 1 , pp. 83-104.

Bakker, A.B., Tims, M. and Derks, D. (2012), "Proactive personality and job performance: The role of job crafting and work engagement", Human Relations, Vol. 65 No. 10, pp. 1359-1378.

Berg, J.M., Dutton, J.B. and Wrzesniewski, A. (2013), "Job Crafting and Meaningful Work", in Dik, B.J., Byrne, Z., S and Steger, M.F. (Eds), Purpose and Meaning in the Workplace, American Psychological Association, Washington, Dc, pp. 81-104.

Berg, J.M., Grant, A.M. and Johnson, V. (2010a), "When Callings Are Calling: Crafting Work and Leisure in Pursuit of Unanswered Occupational Callings", Organization Science, Vol. 21 No. 5, pp. 973-994.

Berg, J.M., Wrzesniewski, A. and Dutton, J.E. (2010b), "Perceiving and responding to challenges in job crafting at different ranks: When proactivity requires adaptivity", Journal of Organizational Behavior, Vol. 31 No. 2-3, pp. 158-186.

Bhagat, R.S. and Allie, S.M. (1989), “Organizational stress, personal life stress, and symptoms of strain: An examination of the moderating role of sense of competence", Journal of Vocational Behavior, Vol. 35 No. 3, pp. 231-253.

Bindl, U.K. and Parker, S.K. (2010), "Proactive work behavior: Forward-thinking and change-oriented action in organizations", in Zedeck, S. (Ed), APA handbook of industrial 
and organizational psychology, American Psychological Association, Washington, DC, pp. 567-598.

Brislin, R.W., Lonnen, W.J. and Thorndike, E.M. (1973), Cross-Cultural Research Methods, Wiley, New York, NY.

Demerouti, E., Bakker, A.B., Nachreiner, F. and Schaufeli, W.B. (2001), “The job demandsresources model of burnout", Journal of Applied Psychology, Vol. 86 No. 3, pp. 499-512.

Ford, M.E. (1985), “The concept of competence: Themes and variations”, in Marlowe, H.A. and Weinberg, R.B. (Eds), Competence Development: Theory and practice in special populations, C.C. Thomas, Springfield, IL, pp. 3-49.

Freedman, S.M. and Phillips, J.S. (1985), “The effects of situational performance constraints on intrinsic motivation and satisfaction: The role of perceived competence and selfdetermination”, Organizational Behavior and Human Decision Processes, Vol. 35 No. 3, pp. 397-416.

Ghitulescu, B.E. (2006), Shaping tasks and relationships at work: Examining the antecedents and consequences of employee job crafting, Unpublished doctoral dissertation, Pittsburgh.

Grant, A.M. and Ashford, S.J. (2008), “The dynamics of proactivity at work”, Research in Organizational Behavior, Vol. 28, pp. 3-34.

Hakanen, J.J., Perhoniemi, R. and Toppinen-Tanner, S. (2008), "Positive gain spirals at work: From job resources to work engagement, personal initiative and work-unit innovativeness", Journal of Vocational Behavior, Vol. 73 No. 1, pp. 78-91.

Hobfoll, S.E. (1989), “Conservation of Resources. A New Attempt at Conceptualizing Stress", American Psychologist, Vol. 44 No. 3, pp. 513-524.

Kira, M., Eijnatten, F.M.v. and Balkin, D.B. (2010), “Crafting sustainable work: development of personal resources", Journal of Organizational Change Management, Vol. 23 No. 5, pp. 616-632. 
Leana, C., Appelbaum, E. and Shevchuk, I. (2009), “Work process and quality of care in early childhood education: the role of job crafting", Academy of Management Journal, Vol. 52 No. 6, pp. 1148-1168.

Lee, F. (1997), "When the Going Gets Tough, Do the Tough Ask for Help? Help Seeking and Power Motivation in Organizations", Organizational Behavior And Human Decision Processes, Vol. 72 No. 3, pp. 336-363.

Llorens, S., Schaufeli, W., Bakker, A. and Salanova, M. (2007), "Does a positive gain spiral of resources, efficacy beliefs and engagement exist?", Computers in Human Behavior, Vol. 23 No. 1, pp. $825-841$.

Lyons, P. (2008), “The Crafting of Jobs and Individual Differences”, Journal of Business and Psychology, Vol. 23 No. 1-2, pp. 25-36.

Mathieu, J.E. and Zajac, D.M. (1990), “A review and meta-analysis of the antecedents, correlates, and consequences of organizational commitment”, Psychological Bulletin, Vol. 108 No. 2, pp. 171-194.

Miller, V.D. and Jablin, F.M. (1991), "Information seeking during organizational entry: Influences, tactics and a model of the process", Academy of Management Review, Vol. 16 No. 1, pp. 92-120.

Ohly, S. and Fritz, C. (2009), "Work characteristics, challenge appraisal, creativity, and proactive behavior: A multi-level study”, Journal of Organizational Behavior, Vol. 31 No. 4, pp. 543-565.

Oldham, G.R. and Hackman, J.R. (2010), "Not what it was and not what it will be: The future of job design research", Journal of Organizational Behavior, Vol. 32 No. 2-3, pp. 463-479.

Parker, S.K. (1998), "Enhancing Role Breadth Self-Efficacy: The Roles of Job Enrichment and Other Organizational Interventions", Journal of Applied Psychology, Vol. 83 No. 6, pp. 835-852. 
Parker, S.K., Wall, T.D. and R, J.P. (1997), "Thats not My Job: Developing Flexible Employee Work Orientations”, Academy of Management Journal, Vol. 40 No. 4, pp. 899929.

Parker, S.K., Williams, H.M. and Turner, N. (2006), "Modeling the antecedents of proactive behavior at work", Journal of Applied Psychology, Vol. 91 No. 91, pp. 636-652.

Petrou, P., Demerouti, E., Peeters, M.C.W., Schaufeli, W.B. and Hetland, D.J. (2012), "Crafting a job on a daily basis: Contextual correlates and the link to work engagement", Journal of Organizational Behavior, Vol. 33 No. 8, pp. 1120-1141.

Podsakoff, P.M., MacKenzie, S.B., Lee, J.Y. and Podsakoff, N.P. (2003), “Common method biases in behavioral research: a critical review of the literature and recommended remedies", Journal of Applied Psychology, Vol. 88 No. 5, pp. 879-903.

Salanova, M. and Schaufeli, W.B. (2008), “A cross-national study of work engagement as a mediator between job resources and proactive behaviour", The International Journal of Human Resource Management, Vol. 19 No. 1, pp. 116-131.

Studenmund, A.H. (2009). Using econometrics. A practical guide, Pearson, Boston.

Tafarodi, R.W. and Swann, W.B. (2001), "Two-dimensional self-esteem: Theory and measurement”, Personality and Individual Differences, Vol. 31, pp. 653-673.

Tims, M. and Bakker, A.B. (2010), “Job crafting: Towards a new model of individual job redesign”, South African Journal of Industrial Psychology, Vol. 36 No. 2, pp. 1-9.

Tims, M., Bakker, A.B. and Derks, D. (2012), "Development and validation of the job crafting scale", Journal of Vocational Behavior, Vol. 80 No. 1, pp. 173-186.

Tims, M., Bakker, A.B. and Derks, D. (2013a), "The Impact of Job Crafting on Job Demands, Job Resources, and Well-Being”, Journal of Occupational Health Psychology, Vol. 18 No. 2, pp. $230-240$. 
Tims, M., Bakker, A.B., Derks, D. and Van Rhenen, W. (2013b), "Job crafting at the team and individual level: Implications for work engagement and performance", Group and Organization Management, Vol. 38 No. 4, pp. 427-454.

Tornau, K. and Frese, M. (2013), “Construct Clean-Up in Proactivity Research: A MetaAnalysis on the Nomological Net of Work-Related Proactivity Concepts and their Incremental Validities”, Applied Psychology, Vol. 62 No. 1, pp. 44-96.

Wrzesniewski, A., Dutton, J. and Debebe, G. (2003), “Interpersonal Sensemaking and the Meaning of Work", Research in Organizational Behavior, Vol. 25, pp. 93-135.

Wrzesniewski, A. and Dutton, J.E. (2001), “Crafting a Job: Revisioning Employees as Active Crafters of Their Work", Academy of Management Review, Vol. 26 No. 2, pp. 179-201. 
Figure 1. Illustration of Job Enlargement x Self-Competence on Increasing Social Job Resources

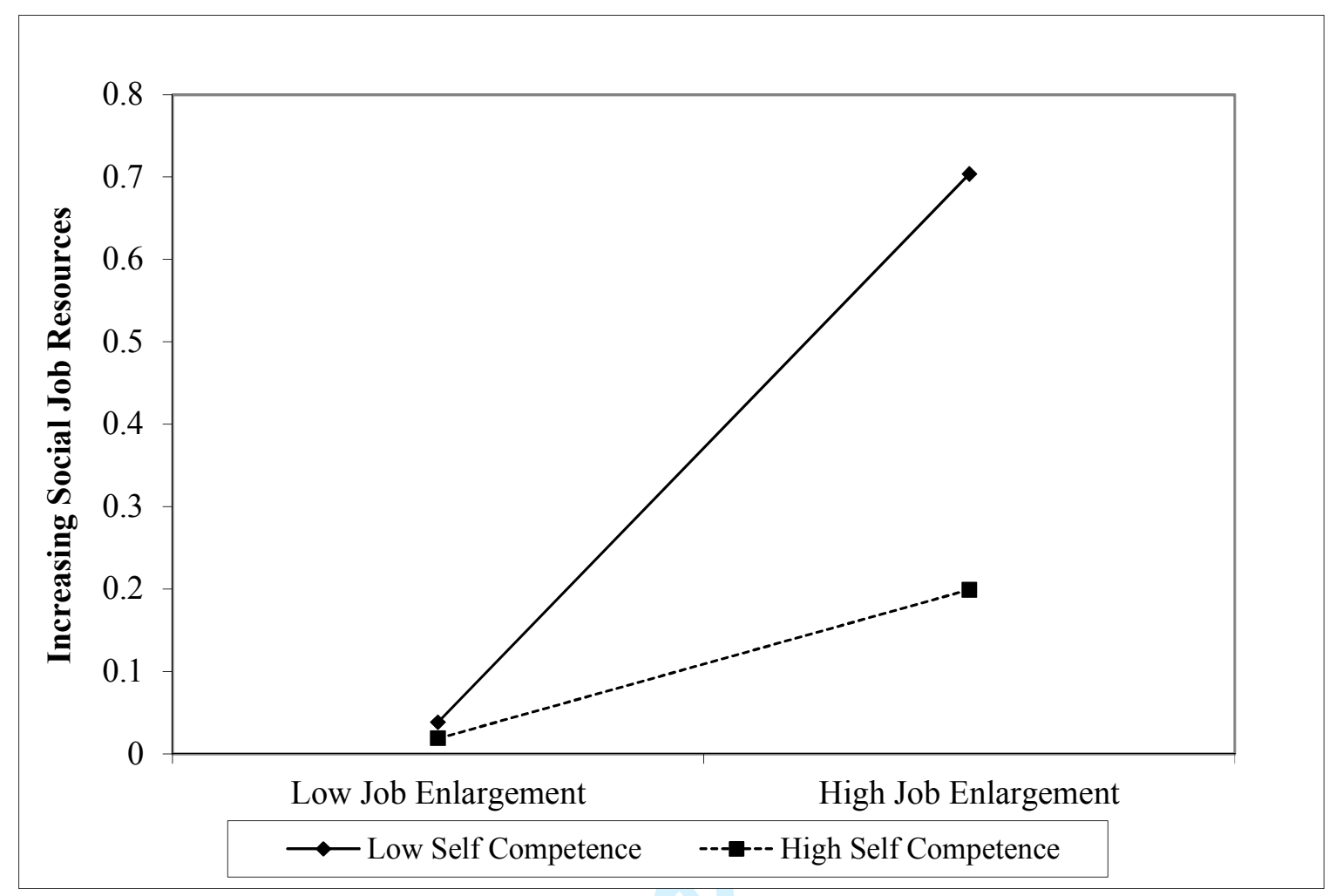




\section{Page 23 of 24}

Journal of Managerial Psychology

Table 1. Descriptive statistics and intercorrelations of the variables

\begin{tabular}{|c|c|c|c|c|c|c|c|c|c|c|}
\hline Variables & Mean & SD & $\mathrm{CR}^{\wedge}$ & $\mathrm{AVE}^{\wedge \wedge}$ & 1 & 2 & 3 & 4 & 5 & 6 \\
\hline 1. Gender & 0.50 & 0.50 & - & - & - & & & & & \\
\hline 2. Tenure & 12.45 & 10.99 & - & - & $-0.25^{\star \star}$ & - & & & & \\
\hline 3. Job Enlargement & 3.97 & 0.70 & 0.742 & 0.590 & -0.08 & -0.03 & $(0.72)$ & & & \\
\hline 4. Self-Competence & 3.51 & 0.55 & 0.845 & 0.579 & 0.13 & 0.03 & $0.26^{* *}$ & $(0.71)$ & & \\
\hline 5. Increasing Structural Resources & 4.11 & 0.56 & 0.844 & 0.647 & 0.08 & $-0.30^{* *}$ & $0.32^{* *}$ & $0.30^{* *}$ & $(0.74)$ & \\
\hline 6. Increasing Social Resources & 2.85 & 0.80 & 0.763 & 0.522 & -0.05 & $-0.50^{* *}$ & $0.21^{* *}$ & $-0.16^{\star}$ & $0.23^{* *}$ & $(0.75)$ \\
\hline
\end{tabular}

Notes: $\mathrm{n}=158 ;{ }^{* \star} \mathrm{p}<0.01 ;{ }^{*} \mathrm{p}<0.05$; The numbers in parentheses are the coefficient alphas; ${ }^{\wedge}$ Composite reliability; ${ }^{\wedge}$ Average variance extracted. 
Table 2. Results of regression analysis

\begin{tabular}{|c|c|c|c|c|c|c|c|c|c|c|c|c|}
\hline \multirow[t]{3}{*}{ Dependent Variable } & \multicolumn{6}{|c|}{ Increasing Structural Job Resources } & \multicolumn{6}{|c|}{ Increasing Social Job Resources } \\
\hline & \multicolumn{2}{|c|}{ Model 1} & \multicolumn{2}{|c|}{ Model 2} & \multicolumn{2}{|c|}{ Model 3} & \multicolumn{2}{|c|}{ Model 1} & \multicolumn{2}{|c|}{ Model 2} & \multicolumn{2}{|c|}{ Model 3} \\
\hline & Beta & $\mathrm{t}$ & Beta & $\mathrm{t}$ & Beta & $\mathrm{t}$ & Beta & $\mathrm{t}$ & Beta & $\mathrm{t}$ & Beta & $\mathrm{t}$ \\
\hline Gender & -0.02 & -0.22 & -0.03 & -0.38 & -0.03 & -0.37 & -0.30 & $-2.63^{* *}$ & -0.21 & $-1.96^{*}$ & -0.21 & $-1.96^{*}$ \\
\hline Tenure & -0.01 & $-3.41^{* *}$ & -0.01 & $-2.78^{* *}$ & -0.01 & $-3.89^{* *}$ & -0.03 & $-7.37^{* *}$ & -0.03 & $-7.41^{* *}$ & -0.03 & $-7.53^{* *}$ \\
\hline Job Enlargement & & & 0.20 & $3.40^{* *}$ & 0.20 & $3.38^{* *}$ & & & 0.29 & $3.70^{\star *}$ & 0.28 & $3.68^{* *}$ \\
\hline Self Competence & & & 0.25 & $3.36^{* *}$ & 0.26 & $3.38^{* *}$ & & & -0.28 & $-2.81^{* *}$ & -0.23 & $-2.34^{*}$ \\
\hline Job Enlargement x Self Competence & & & & & -0.05 & -0.49 & & & & & -0.33 & $-2.47^{*}$ \\
\hline$R^{2}$ & 0.07 & & 0.23 & & 0.23 & & 0.26 & & 0.35 & & 0.37 & \\
\hline $\mathrm{F}$ & $6.12^{* *}$ & & $11.53^{* *}$ & & $9.23^{* *}$ & & $27.33^{\star *}$ & & $16.40^{\star *}$ & & $14.74^{\star *}$ & \\
\hline Degrees of freedom & 3 & & 5 & & 6 & & 3 & & 5 & & 6 & \\
\hline VIF & 1.09 & & 1.11 & & 1.10 & & 1.09 & & 1.11 & & 1.10 & \\
\hline $\mathrm{N}$ & 158 & & 158 & & 158 & & 158 & & 158 & & 158 & \\
\hline
\end{tabular}

